Ege Tıp Dergisi / Ege Journal of Medicine 2021; 60 (3): 210-218

\title{
Spora katılımın ergenlik dönemindeki depresyon ve kaygı düzeylerine etkisi
}

The effect of participation in sports on depression and anxiety levels in adolescence

\author{
Seçkin Şenışık ${ }^{1}$ Hakan Kayış ${ }^{2}$ (iD \\ ${ }^{1}$ Ege Üniversitesi Tıp Fakültesi Spor Hekimliği Anabilim Dalı, İzmir, Türkiye \\ ${ }^{2}$ Bitlis Tatvan Devlet Hastanesi, Çocuk ve Ergen Ruh Sağlığı ve Hastalıkları Birimi, Bitlis, Türkiye
}

Öz

Amaç: Düzenli yapılan egzersizin başta depresyon ve kaygı bozuklukları olmak üzere birçok ruh sağlığı bozukluğu riskini azaltabildiği gösterilmiştir. Bu çalışmanın amacı düzenli egzersizin ergenlerde depresyon ve kaygı düzeyleri üzerine etkisini araştırmaktır.

Gereç ve Yöntem: Çalışmaya yaş ortalaması 16 olan 42 kız basketbol sporcusu ve benzer yaşlardaki düzenli spor yapmayan kızlar katılmıştır. Egzersizin ruh sağlığı üzerindeki etkilerini değerlendirebilmek amacı ile katılımcılara psikiyatrik muayene yapılmış, Okul Çağı Çocukları İçin Duygulanım Bozuklukları ve Şizofreni Görüşme Çizelgesi-Şimdi ve Yaşam boyu Şekli Türkçe uyarlaması (ÇDŞGŞY), Beck depresyon ölçeği, Beck kaygı ölçeği, Yeme tutumu testi - 40 (YTT - 40) ve Beden algısı ölçekleri uygulanmıştır. İstatiksel yöntem olarak ölçekler kesme puanlarına göre kategorize edildikten sonra gruplar arasında karşılaştırma yapmak amacı ile Pearson ki-kare testi uygulanmıştır. Parametreler arasında ilişki olup olmadığını incelemek için Spearman korelasyon testi yapılmıştır.

Bulgular: Düzenli olarak spor yapan kişilerin depresyon ve kaygı düzeyleri istatiksel olarak anlamlı düzeyde daha düşük olarak saptanmıştır ( $p=0,041$ ve $p=0,002$; sırasıyla). Yeme davranışlarındaki bozukluk riski düzenli egzersiz alışkanlığı olmayan kızlarda daha yüksek bulunmuştur $(p=0,023)$. Beden algısı açısından ise gruplar arasında anlamlı bir fark gözlenmemiştir $(p=0,682)$. Beden algısı ile depresyon ve kaygı düzeyleri arasında istatiksel olarak anlamlı düzeyde negatif bir ilişki gözlenmiştir ( $r=-0,396, p=0,000 ; r=-0,437, p=0,000$; sırasıyla).

Sonuç: Bu çalışmanın sonucuna göre düzenli yapılan egzersizin ergenlerde depresyon ve kaygı düzeylerini azaltabileceği düşünülmektedir. Özellikle de aktivite düzeyi az olan ergenlerin spora katıımlarının teşvik edilmesi, ruh sağlıklarının gelişmesine katkıda bulunabilir.

Anahtar Sözcükler: Egzersiz, depresyon, kaygı, ruhsal sağlık.

\section{ABSTRACT}

Aim: Regular exercises have been shown to reduce the risk of many mental health problems, especially depression and anxiety. The aim of this study was to investigate the effect of regular exercise on depression and anxiety levels in adolescents.

Materials and Methods: 42 girls basketball players with an average age of 16 and girls of similar ages who don't exercise regularly participated in the study. In order to evaluate the effects of exercise on mental health, psychiatric examination, K-SADS-PL (Schedule for Affective Disorders and Schizophrenia for School Aged Children, Present and Lifetime Version), Beck depression scale, Beck anxiety scale, Eating attitude test - 40 (EAT - 40) and Body image scales were performed. As the statistical method, Pearson chi-square test was used to compare the groups after the scales were categorized according to cut-off scores. Spearman correlation test was performed to examine whether there is a relationship between parameters.

\footnotetext{
Sorumlu yazar: Seçkin Şenışık

Ege Üniversitesi Tıp Fakültesi Spor Hekimliği Anabilim Dalı,

İzmir, Türkiye

E-posta: seckinsnsk@gmail.com

Başvuru tarihi: 04.05.2020 Kabul tarihi: 03.02.2021
} 
Results: Depression and anxiety levels of girls who exercise regularly were statistically significantly lower ( $p=0.041$ and $p=0.002$; respectively). The risk of eating disorders was found higher in girls without regular exercise habits $(p=0.023)$. In terms of body perception, there was no significant difference between the groups $(p=0.682)$. There was a statistically significant negative relationship between body perception and depression and anxiety levels $(r=-0.396, p=0.000 ; r=-0.437$, $p=0.000$; respectively).

Conclusion: It is seen that regular exercises can decrease depression and anxiety levels. To improve the mental health of adolescents with low activity levels by increasing the participation in sports is possible.

Keywords: Exercise, depression, anxiety, mental health.

\section{GiRiş}

Günümüzde birçok ergen ruh sağlığı sorunlarından etkilenmektedir. Ergenlik 0 dönemdeki sağlığı etkilemesinin yanı sıra yetişkinlik dönemindeki fiziksel ve ruhsal bozukluklara da neden olan davranışların başlangıcı olan bir dönemdir. Sigara, alkol ve madde kullanımı gibi sağlıksız alışkanlıklar sıklıkla ergenlik döneminde başlar ve hastalık ve ölüm oranlarında artış ile yakın ilişkilidir (1). Yetişkinlikteki ruh sağı̆ğı hastalıklarının \%50'den fazlasının başlangıcı 18 yaşından öncedir (2). Birçok ülkede çok merkezli olarak yapılan bir çalışmada ergenlerin \%5,8'inde kaygı bozukluğu, $\% 10,5$ 'inde depresif bozukluk (3) ve \%32,3'ünde intihar düşünceleri (4) olduğu belirtilmiştir. Bu denli ciddi oranlarda görülen bozuklukları önlemek, tedaviyi faydalı olabilecek uygulamalarla güçlendirmek, toplum sağlığı açısından oldukça faydalı olacaktır.

Dünya çapında ergenlerde en sık görülen ruh sağlığı bozukluğu depresyondur. Dünya sağlık örgütüne göre depresyon dünya çapında bir hastalıktır ve 260 milyonun üzerinde insanı etkilemektedir $(5,6)$. Sıklıkla kronik ve tekrarlayıcı bir durumdur. Yüksek düzeyde psikolojik stres, işlevsellikte bozulma, obezite gibi kötü fiziksel sağlık ve kötü sosyal ve akademik sonuçlar ile ilişkilidir $(7,8)$.

Çocuklarda depresyon ve diğer duygu durum bozuklukları \%1'den daha az düzeyde iken ergenliğe doğru artmaya başlar ve ergenlik sonunda \%20 seviyelerine ulaşır (7). Depresyon bulguları olan ergenlerin aynı zamanda intihar açısından da yüksek risk altında olduğu görülmektedir (9). Depresyona bağlı ölüm oranı yaklaşık \%4'tür. Depresyonun ergenlik dönemindeki belirtileri erken yetişkinlikte de devam edebilir. Depresyonu olan ergenlerin stres düzeyleri yüksek, alkol ve sigara kullanımı ve çeşitli sağlık sorunları olan genç yetişkinlere dönüşme olasılığı yüksektir (10). Depresyonun yanı sıra kaygı bozuklukları da çocukluk ve ergenlik döneminde işlevselliği etkileyen ruh sağlığı bozukluklarındandır. Çocukların \%5-10'u ve ergenlerin \%25 kadarı kaygı bozukluklarından etkilenmektedir ve kaygı bozukluklarının da erken ölüm riskinde artış ile ilişkili olduğu gösterilmiştir $(11,12)$.

Beden algısı, bir kişinin kendi fiziksel görünümüne karşı nasıl düşündüğü, davrandığı ve hissettiği çok boyutlu bir yapıdır. Beden algısı düşük olan insanlar kendilerini çirkin veya aşırı kilolu, kas yapısı yetersiz veya çok ince ve zayıf olarak algılayabilirler. Ergenler puberte ile birlikte vücutlarının veya görünümlerinin ideal beden algılarından farklı olduğunu düşünebilir ve bedenlerinden hoşnutsuz olabilirler (13). Sonuç olarak, bu kişiler depresyon, stres, kaygı ve yeme bozuklukları açısından risk altındadırlar (14).

Beslenme ve yeme bozuklukları, bireylerde fiziksel ve ruhsal sağlık sorunlarından ölümcül sonuçlara kadar değişen olumsuz etkilere neden olmaktadır. Birçok genç yetişkin için ergenlik döneminde meydana gelen fiziksel görünümdeki değişikliklere uyum sağlamak oldukça sıkıntılı bir süreçtir. Bu dönem kişinin üzerinde stres yükü oluşturarak düzensiz yeme alışkanlıklarında rol oynayabilir. Depresyon bulguları ile yeme psikopatolojisi sıklıkla birbirine eşlik eden bozukluklardır (15).

Depresyon ve kaygı gibi ruh sağlığı bozukluklarının belirtilen yıkıcı ve zararlı etkilerinden dolayı, bu problemleri önlemek veya tedavi etmek amacı ile etkili yöntemlerin tanımlanması ve uygulanması önemlidir. Yüksek görülme sıklıklarından dolayı, hastalığın erken dönemlerinde ruh sağlığını geliştirmeye yönelik müdahalelerin uygulanması gerekmektedir. Bu nedenle, ergenlerde depresyon ve kaygı ile ilişkili faktörlerin mutlaka araştırılması gerekmektedir (16). 
Egzersizin kalp-damar hastalıkları, bazı kanser tipleri ve şeker hastalığı risklerini azaltma gibi fiziksel yararlarının yanı sıra; egzersiz yapanlarda genel olarak iyi hissetme ve pozitif ruh haline sebep olması, kaygı ve depresyon düzeylerini düşürmesi gibi psikolojik faydaları olduğu da gösterilmiştir $(17,18)$. Herkes tarafından kabul edilen, çok az yan etkisi olan ve gençlerin ruh sağlığını geliştirmeye veya ruh sağlığı problemlerini tedavi etmeye yardımcı bir yöntem olarak görülmektedir (19). Ergenlerin fiziksel sağlığının sık yapılan egzersiz ile arttığına dair kanıtlar vardır. Bu pozitif inanışlara rağmen düzenli egzersiz ve spora katılım düzeyleri ergenlik sırasında gittikçe azalmaktadır (20). 5-17 yaş arasındaki çocukların ve ergenlerin her gün en az 60 dakika süre ile orta-yüksek şiddette aktivite yapmaları önerilmektedir (21). Bununla birlikte dünya genelinde 13-15 yaş arasındakilerin yaklaşık \%80'inin bu günlük aktivite miktarını karşılamadıkları belirtilmiştir (20).

$\mathrm{Bu}$ çalışmanın amacı düzenli spor yapan ve yapmayan ergenler arasında depresyon ve kaygı düzeylerinin farklı olup olmadığını ve depresyon ve kaygı düzeyleri ile beden algısı ve yeme tutumu arasında ilişki olup olmadığını araştırmaktır. Çalışmadaki hipotez düzenli spor yapan ergenlerde egzersizin beden algısı ve yeme tutumunu olumlu yönde etkileyerek depresyon ve kaygı düzeylerinin azalmasını sağlayacağıdır.

\section{GEREÇ ve YÖNTEM}

En az beş yıldır haftada en az dört gün düzenli olarak spor yapan 42 ergen kız ve benzer yaşlardaki spor yapmayan 35 gönüllü kız öğrenci çalışmaya katıldı. Spor yapmayan grup hastane çalışanlarının yakınlarından oluşturuldu. Spor yapan grup, İzmir'de bir basketbol takımının U18 gençler (17-18 yaş), U16 yıldızlar (15-16 yaş) ve U14 küçükler (13-14) yaş kategorilerindeki 14-18 yaş arası sporcularından oluşturuldu. Psikiyatrik takip ve tedavi öyküsü olan, madde kullanım öyküsü olan, klinik olarak zekâ geriliği olan olgular çalışmadan dışlanmıştır. Psikiyatrik muayene ve ÇDŞG-ŞY sonrası işlevselliği bozacak düzeyde bir psikiyatrik bozukluğa sahip olduğu saptanan olgular tedavi amacıyla yönlendirilmiştir. Katılımcıların boyu $(\mathrm{cm})$ ve ağırlık ölçümü duvara monte boy ölçer ve dijital skala kullanılarak yapılmıştır. Ardından elde edilen bu değerler kullanılarak vücut kitle indeksi $\left(\mathrm{kg} / \mathrm{m}^{2}\right)$ hesaplanmıştır. Çalışmaya katılan kişilerin özellikleri Tablo-1'de verilmiştir.
Çalışma, kesitsel çalışma olarak düzenlenmiştir. Çocuk ve ergen ruh sağlığı uzmanı tarafından değerlendirilip ÇDŞG-ŞY uygulandıktan sonra katılımcılara depresyon, kaygı, beden algısı ve yeme tutumu düzeylerini değerlendiren ölçekler uygulanmıştır. Çalışmaya katılacak ergenlere ve ailelere çalışmanın amacı ve prosedürü hakkında bilgi verilmiş ve tıbbi verilerinin yayınlanabileceğine ilişkin yazılı onam belgesi alınmıştır. Çalışma için Ege Üniversitesi Tıp Fakültesi Tıbbi Araştırmalar Etik Kurulundan 17.10.2018 tarih ve $18-10.1 \mathrm{~T} / 23$ numaralı izin yazısı alınmıştır.

Okul Çağı Çocukları İçin Duygulanım Bozuklukları ve Şizofreni Görüşme ÇizelgesiŞimdi ve Yaşam Boyu Şekli Türkçe Uyarlaması-ÇDŞG-ŞY (Schedule for Affective Disorders and Schizophrenia for School Aged Children, Present and Life time Version, $K$ SADS-PL) (22): ÇDŞG-ŞY çocuk ve ergenlerde şimdiki ve yaşam boyu olan psikopatolojileri saptamak amacıyla kullanılan yarı yapılandırımış bir görüşme formudur. Form üç bölümden oluşmaktadır. İlk bölümde çocuğun demografik özellikleri, genel sağlık durumu, varsa daha önceki psikiyatri başvurusu ve tedavisi, aile ve akran ilişkileri, okul bilgileri gibi genel bilgiler sorgulanır. İkinci bölüm özgül psikiyatrik belirtilerin sorgulandığı tarayıcı sorular ve değerlendirme ölçütlerini içermektedir. Tarama görüşmesi ile pozitif belirtiler varsa o psikopatolojiyi daha iyi değerlendirmek amacıyla ek belirti listesi sorgulanmaktadır. Belirtilerin varlığına ve şiddetine çocuğun ya da ergenin, anne babanın ve hekimin görüşleri birleştirilerek karar verilmektedir. ÇDŞG-ŞY ile duygu durum bozuklukları, psikotik bozukluklar, kaygı bozuklukları, dışa atım bozuklukları, yıkıcı davranım bozuklukları, madde kötüye kullanımı, yeme bozuklukları ve tik bozuklukları değerlendirilebilmektedir. Üçüncü bölüm çocuğun değerlendirme yapıldığı zamanda işlev düzeyini belirlemek amacıyla kullanılan genel değerlendirme ölçeğidir. Ölçeğin Türk örneklemi için geçerlik ve güvenirlik çalışması yapıımıştır (23).

Beck Depresyon Ölçeği: Beck ve arkadaşları (24) tarafından oluşturulmuş olan bu ölçeğin Türkçe için geçerlik ve güvenirlik çalışması Hisli (25) tarafından yapılmıştır. Uygulanma amacı depresyon tanısı koymak değil, depresif belirtilerin düzeyini ve şiddet değişimini ölçmektir. Dört dereceli Likert tipi 21 ifadeden oluşmaktadır. 
Hastadan son bir hafta içindeki belirtileri "hiç yok, hafif düzeyde, orta düzeyde, ciddi düzeyde var" şeklinde değerlendirmesi istenir. Her madde 0-3 arasında puan alır ve bunların toplanması ile toplam puan elde edilir (0-63 puan). Ölçeğin kesme puanı 17 olarak belirlenmiştir. Toplam puanın yüksek olması depresyon düzeyinin yüksekliğini gösterir.

Beck Kaygı Ölçeği: Beck, Epstein, Brown ve Steer tarafından 1988'de geliştirilmiştir (26). Bireylerin yaşadığı kaygı belirtilerinin sıklığını ve şiddetini belirlemeyi amaçlayan, kendini değerlendirme ölçeğidir. Her maddesi $0-3$ arasında puan alan Likert tipi 21 maddeden oluşan ölçekten alınabilecek en yüksek puan 63 'tür. Hastadan son bir hafta içindeki belirtileri değerlendirmesi istenir. Her bir belirti "hiç yok, hafif düzeyde, orta düzeyde, ciddi düzeyde" var şeklinde değerlendirilir. Ölçeğin kesme puanı 15 'tir. Türkiye'deki geçerlik ve güvenilirliği Ulusoy, Şahin ve Erkman (27) tarafından yapılmıştır.

Yeme Tutumu Testi - 40 (YTT - 40): Yeme davranışlarındaki olası bozuklukları değerlendirmek için kullanılan öz bildirim ölçeğidir. Garner ve Garfinkel (28) tarafından geliştirilmiştir. Test 40 sorudan oluşmakta, cevaplar "daima - hiçbir zaman" şeklinde altı basamaklı Likert formunda değerlendirilmektedir. YTT - 40 ölçeği için kesme puanı 30'dur. Puanın 30 'un üzerinde olması yeme tutumunun bozuk olduğunu göstermektedir. Ölçeğin Türkçe güvenirlik ve geçerliği Savaşır ve Erol (29) tarafından yapılmıştır.

Beden Algısı Ölçeği: 1953 yılında Secord ve Jourand (30) tarafından geliştirilmiş bir ölçektir. Bedenin bir bölümü (kol, bacak, yüz gibi) ya da bir işlevi (cinsel faaliyet düzeyi gibi) ile ilgili "hiç beğenmiyorum - çok beğeniyorum" şeklinde 5 dereceli Likert tipi cevaplanan 40 maddeden oluşmaktadır. Toplam puanı 40 ile 200 arasında değişmektedir. Ölçeğin kesme puanı 135 olup, 135 altında puana sahip olanlar beden algısı düşük grup olarak tanımlanmıştır. Hovardaoğlu (31) tarafından Türkçe geçerlik ve güvenirlik çalışması yapılmıştır.

SPSS Versiyon 25.0 veri analizleri için kullanıldı. Katılımcı özelliklerinin incelenmesinde betimleyici analiz kullanıldı. Verilerin dağılımının normal olup olmadığını değerlendirmek amacıyla Shapiro Wilk normallik testi yapıldı. $p<0,05$ olduğu için verilerin dağılımının normal olmadığı düşünülerek parametrik olmayan testler uygulandı. Gruplar arasında parametreler açısından fark olup olmadığını incelemek için Mann-Whitney testi uygulandı. Ölçekler kesme puanlarına göre kategorize edildikten sonra spor yapmanın beden algısı, yeme tutumu, depresyon ve kaygı düzeyleri üzerinde etkisinin olup olmadığını değerlendirmek amacı ile Pearson ki-kare testi yapıldı. Parametrelerin birbiri arasında ilişki olup olmadığını incelemek için Spearman korrelasyon testi uygulandı. $p<0,05$ değeri istatiksel olarak anlamlı kabul edildi.

\section{BULGULAR}

Örneklem benzer yaşlardaki katılımcılardan oluşmaktaydı. Sporcuların yaş ortalaması 16, spor yapmayan kişilerin yaş ortalaması ise 17 idi. Sporcuların boy, kilo ve vücut kitle indeksleri (VKI) spor yapmayan kişilere göre istatiksel olarak anlamlı düzeyde daha yüksekti $(p<0,05)$ (Tablo-1).

Spor yapmayan kişilerde yeme tutumu testi $(p=0,001)$ ve Beck kaygı ölçeği $(p=0,025)$ sonuçları istatiksel olarak anlamlı düzeyde daha yüksekken, beden algısı ölçeği $(p=0,598)$ ve Beck depresyon testleri $(p=0,096)$ açısından anlamlı farklılık yoktu (Tablo-2). Psikiyatrik değerlendirme ve ölçekler göz önüne alındığında spor yapmayan ergenlerde hem depresyon hem de kaygı bozukluğunun sporcu gruba göre daha sık gözlendiği görüldü. Ölçekler kesme puanlarına göre kategorize edilip kesme puanlarının altında ve üstünde olan değerlere göre grupların karşılaştırması yapıldığında spor yapan kızların depresif bozukluk ve kaygı bozukluğu puanları spor yapmayanlara göre istatistiksel olarak anlamlı düzeyde daha azdı ( $p$ $=0,041$ ve $p=0,002$; sırasıyla). Sporcu olmayan kızlarda yeme davranışlarındaki bozukluk riski sporculara göre istatiksel olarak anlamlı düzeyde daha yüksek iken beden algısı açısından gruplar arasında anlamlı bir farklılık yoktu ( $p=0,023$ ve $p$ $=0,682$; sırasıyla) (Tablo-3).

Spearman korelasyon analizine göre parametreler arasında ilişki olup olmadığı incelendiğinde beden algısı ile depresyon ve kaygı arasında istatiksel olarak anlamlı düzeyde negatif bir ilişki bulundu $(r=-0,396, p=0,000 ; r$ $=-0,437, p=0,000 ;$ sırasıyla). Yeme tutumu ile kaygı düzeyi arasında anlamlı ölçüde pozitif yönde bir ilişki varken, yeme tutumu ile depresyon düzeyi ve beden algısı arasında ilişki yoktu $(r=0,280, p=0,014 ; r=0,214, p=0,062 ; r$ $=0,167, p=0,147$; sırasıyla) (Tablo-4). 
Tablo-1. Çalışmaya katılan kişilerin özellikleri.

\begin{tabular}{ccccc}
\hline & $\begin{array}{c}\text { Yaş } \\
(\mathbf{y ı l})\end{array}$ & $\begin{array}{c}\text { Ağırlık } \\
\text { (Kilo) }\end{array}$ & $\begin{array}{c}\text { Boy } \\
\text { (cm) }\end{array}$ & $\begin{array}{c}\mathbf{V K i}^{*} \\
\left(\mathbf{k g} / \mathbf{m}^{\mathbf{2}}\right)\end{array}$ \\
\hline Spor Yapmayan & 17 & 55 & 170 & 19,7 \\
$(\mathrm{n}=35)$ & $(16-18)$ & $(43-100,6)$ & $(150-190)$ & $(16,7-35,6)$ \\
Spor Yapan & 16 & 68 & 176,5 & 21,5 \\
$(\mathrm{n}=42)$ & $(14-18)$ & $(54-83)$ & $(165-190)$ & $(17,8-25,5)$ \\
\hline
\end{tabular}

*: VKI; Vücut kitle indeksi

Tablo-2. Spor yapan ve yapmayan kişilerin test sonuçları.

\begin{tabular}{ccccc}
\hline & $\begin{array}{c}\text { Yeme Tutumu } \\
\text { Testi }\end{array}$ & $\begin{array}{c}\text { Beden Algısı } \\
\text { Ölçeği }\end{array}$ & $\begin{array}{c}\text { Beck Depresyon } \\
\text { Ölçeği }\end{array}$ & Beck Kaygı Ölçeği \\
\hline Spor Yapmayan & 26 & 154 & 12 & 11 \\
$(\mathrm{n}=35)$ & $(12-120)$ & $(122-196)$ & $(0-41)$ & $(0-35)$ \\
Spor Yapan & 17 & 156 & 10 & 6 \\
$(\mathrm{n}=42)$ & $(8-61)$ & $(117-199)$ & $(0-35)$ & $(0-43)$ \\
Mann-Whitney testi & $\mathrm{p}=0,001^{* *}$ & $\mathrm{p}=0,598$ & $\mathrm{p}=0,096$ & $\mathrm{p}=0,025^{*}$ \\
\hline
\end{tabular}

Veriler ortalama (minimum-maksimum) şeklinde verilmiştir.

${ }^{*}: p<0,05,{ }^{* *}: p<0,01$

Tablo-3. Spor yapan ve yapmayan kişilerin test sonuçları.

\begin{tabular}{|c|c|c|c|c|c|c|c|c|}
\hline & \multicolumn{2}{|c|}{$\begin{array}{c}\text { Yeme Tutumu } \\
\text { Testi }\end{array}$} & \multicolumn{2}{|c|}{$\begin{array}{l}\text { Beden Algısı } \\
\text { Ölçeği }\end{array}$} & \multicolumn{2}{|c|}{$\begin{array}{c}\text { Beck Depresyon } \\
\text { Ölçeği }\end{array}$} & \multicolumn{2}{|c|}{ Beck Kaygı Ölçeğ } \\
\hline & $<30$ & $\geq 30$ & $<135$ & $\geq 135$ & $<17$ & $\geq 17$ & $<15$ & $\geq 15$ \\
\hline $\begin{array}{l}\text { Spor Yapmayan } \\
(n=35)\end{array}$ & 20 & 15 & 8 & 27 & 22 & 13 & 20 & 15 \\
\hline $\begin{array}{l}\text { Spor Yapan } \\
\quad(n=42)\end{array}$ & 34 & 8 & 8 & 34 & 35 & 7 & 37 & 5 \\
\hline $\begin{array}{c}\text { Pearson Ki kare } \\
\text { Testi }\end{array}$ & \multicolumn{2}{|c|}{$p=0,023$} & \multicolumn{2}{|c|}{$p=0,682$} & & & \multicolumn{2}{|c|}{$p=0,002$} \\
\hline
\end{tabular}

${ }^{*}: p<0,05,{ }^{* *}: p<0,01$

Tablo-4. Spearman Korelasyon Testi sonucuna göre parametreler arasındaki ilişki analizi.

\begin{tabular}{ccccc}
\hline & Yeme Tutum Testi & $\begin{array}{c}\text { Beden Algısı } \\
\text { Ölçeği }\end{array}$ & $\begin{array}{c}\text { Beck } \\
\text { Depresyon } \\
\text { Ölçeği }\end{array}$ & Beck Kaygı Ölçeği \\
\hline $\begin{array}{c}\text { Yeme Tutum } \\
\text { Testi }\end{array}$ & 1 & $r=0,167$ & $r=0,214$ & $r=0,280$ \\
Beden Algısı & $r=0,167$ & $p=0,147$ & $p=0,062$ & $p=0,014^{*}$ \\
Ölçeği & $p=0,147$ & & $r=-0,396$ & $r=-0,437$ \\
Beck & $r=0,214$ & $r=-0,396$ & $p=0,000^{* *}$ & $p=0,000^{* *}$ \\
Depresyon Ö. & $p=0,062$ & $p=0,000^{* *}$ & 1 & $p=0,677$ \\
Beck Kaygı Ö. & $r=0,280^{*}$ & $r=-0,437^{* *}$ & $r=0,677^{* *}$ & 1 \\
\hline
\end{tabular}

${ }^{*}: p<0,05,{ }^{* *}: p<0,01$ 


\section{TARTIŞMA}

$\mathrm{Bu}$ çalışmada uzun süre yapılan düzenli egzersizin ergenlerde kaygı ve depresyon düzeyleri üzerine etkisi araştırılmıştır. $\mathrm{Bu}$ çalışmanın temel bulgusu egzersiz yapan ergenlerde kaygı ve depresif belirti düzeylerinin daha düşük olmasıdır. Beden algısı düşük olan ergenlerde kaygı ve depresyon düzeylerinin arttığı bulunmuştur. $\mathrm{Bu}$ bulgular ileride oluşabilecek depresyon ve kaygı bozukluklarının riskini azaltmada egzersizin etkili olabileceğini düşündürmektedir.

Egzersiz düzeyleri çocukluktan ergenliğe doğru kademeli olarak azalmaktadır. Fiziksel aktivitenin azalması ve hareketsiz yaşam, depresyon ve kaygı bozuklukları risklerini artırır (32-34). Düzenli yapılan egzersizin ergenlerde depresyon riskini azalttığını ve koruyucu etkisi olduğunu gösteren çok sayıda çalışma mevcuttur (35-37). Çocuklarda ve ergenlerde kaygı bozuklukları ve depresyona yönelik yapılan randomize kontrollü egzersiz çalışmalarının sistematik derlemesinde, düzenli yapılan egzersizin depresyon ve kaygı düzeylerini azalttığını destekleyen bulgular bildirilmiştir $(38,39)$. Düzenli yapılan egzersizin bedeni daha olumlu algılamayı sağlayarak depresif bulgularda azalma sağladığı gösterilmiştir (40). Spora katılımın aynı zamanda intihar düşüncesi düzeylerinde azalmaya neden olduğu bulunmuştur (41). Herhangi bir egzersiz yapmayan kişiler ile haftada en az bir gün egzersiz yapanların karşılaştırıldığı bir çalışmada egzersiz yapmayanlarda daha fazla depresyon ve kaygı belirtileri olduğu bulunmuştur (34). Bu çalışmada ergenliğin sonlarına doğru egzersiz düzeyinin azalması ile depresyon ve kaygı bozuklukları risklerinin artmasından dolayı 14 yaş üstü ergen kızlar çalışmaya alınmıştır. Çalışmanın sonunda önceki çalışmalarla uyumlu olarak hareket düzeyi az, haftada birden az egzersiz yapan kızlarda depresyon ve kaygı düzeylerinin daha yüksek olduğu bulunmuştur. Egzersiz yapmayan kişiler zihinlerindeki negatif düşüncelere odaklanabilir ve kendileri ile ilişkili yetersiz ve değersiz olduklarına dair olumsuz düşünce uğraşları giderek artabilir. Olumsuz düşünce uğraşlarının artması bu kişilerde zamanla depresif belirtilerin gelişmesine yol açabilir. Bu çalışmanın sonuçları düzenli egzersizin depresyon ve kaygı bozukluklarına karşı koruyucu bir enstrüman olarak kullanılabileceğini gösteriyor olabilir.

Egzersizin kaygı bozuklukları olsun veya olmasın kaygı giderci etkileri olduğu gösterilmiştir. Yüksek egzersiz düzeylerinin ileri yaşlarda oluşabilecek kaygı bozukluklarının riskinde azalma ile ilişkili olduğu gösterilmiştir $(32,42)$. Bir meta-analizde egzersizin kaygı bozukluğu riskini azalttığı, egzersiz düzeyi yüksek olan kişilerde kaygı bozukluğu gelişme riskindeki azalmanın daha belirgin olduğu bulunmuştur (43). Bizim çalışmamızda da literatürle uyumlu olarak egzersiz yapan kızlarda kaygı düzeyleri daha düşük bulunmuştur. Spor yapan kişilerde kendileri ile ilgili etkin ve yeterli olduklarına dair olumlu düşünceler oluşmaktadır. Bu düşünceler de kişinin kendisine güvenini artırarak kaygı düzeyinde azalmaya yardımcı olabilir. Çalışmamızda yer alan sporcular en az beş yıldır düzenli olarak spor katılımı olan kızlardı. Bu kadar uzun süreli spor yapan kişilerde de bu tarz olumlu düşünceler oluşarak kaygı ve depresyon düzeylerinin azalmasını sağlamış olabilir.

Beden algısı kişinin kendi fiziksel görünümüne karşı nasıl hissettiği ile ilgili çok boyutlu bir yapıdır. Olumsuz beden algısı duygu durum bozukluğu, depresyon, kaygı ve yeme bozuklukları ile ilişkilidir $(44,45)$. Egzersizin vücut yapısında gelişmeler sağlayarak beden algısı üzerine olumlu etkilerinin olduğu gösterilmiştir $(46,47)$. Bizim çalışmamızda gruplar arasında beden algısı açısından fark olmamasına rağmen, önceki çalışmalarla uyumlu olarak beden algısı ile depresyon ve kaygı düzeyleri arasında negatif bir ilişki mevcuttu. Çalışmaya katılan düzenli egzersiz yapmayan ergenlerin vücut kitle indekslerinin düşük olması bu kişilerde beden algısında bozulma olmamasını açıklayabilir. Katılımcılar arasında istatiksel olarak anlamlı fark olmamasına rağmen beden algısının depresyon ve kaygı düzeyi ile negatif yönde ilişkisinin olmasını göz önünde bulundurduğumuzda bu kişilerde beden algısı bozuldukça depresyon ve kaygı bozuklukları risklerinin artabileceğini söylemek mümkün görünmektedir.

Yeme bozuklukları bireylerde fiziksel ve psikolojik sağlık sorunlarına sebep olabilir. Ergenlik dönemi birçok genç için meydana gelen fiziksel görünümdeki değişikliklere uyum sağlamak açısından sıkıntılı bir süreçtir. Kişilerin üzerinde stres artışına neden olarak düzensiz yeme alışkanlıklarında rol oynayabilir. Yeme problemleri kişilerin bedeninden hoşnut olmaması olarak ifade edilen fiziksel değişikliklere yanıt olarak oluşabilir. Zamanla depresyon bulgularının ortaya çıkmasına neden olabilir. Depresyon bulguları ve yeme bozuklukları sıklıkla birbirlerine eşlik etmektedir (15). Çalışmamızda spor yapmayan kızlarda yeme davranışlarındaki bozukluk riski daha fazlaydı. $\mathrm{Bu}$ kişilerde 
depresyon ve kaygı düzeyleri de daha yüksek düzeydeydi. Bu bulguları birlikte ele aldığımızda, egzersiz yapmamanın ve vaktinin çoğunu hareketsiz geçirmenin kişinin kendisi ile ilgili yetersizlik düşüncelerinin gelişmesine ve zihninde olumsuz düşüncelerin oluşmasına neden olduğunu, böylece depresyon ve kaygı düzeylerinin artmasının yanında, kişilerin yeme davranışlarında bozulma riskinin artmasına da sebep olduğunu söyleyebiliriz.

Egzersizin ruh sağlığı problemleri üzerindeki etkisini açıklayabilmek amacıyla bazı hipotezler öne sürülmüştür. Bunlar arasında zihinsel arınma hipotezi, kişisel etkinlik hipotezi ve yeterlik hipotezi gibi psikolojik teoriler ve monoamin hipotezi, endorfin yanıtı, nörogenezis hipotezi ve hipotalamus - hipofiz - adrenal aks hipotezi gibi biyokimyasal teoriler bulunmaktadır (48). Bu mekanizmalar arasında öne sürülen bir başka hipotez de sosyal etkileşim hipotezidir. Düzenli yapılan egzersizin sosyal aktivite düzeyini artırarak ruh sağlığı geliştirme üzerinde olumlu etkisi olduğu belirtilmiştir (49). Sosyal etkileşimi yüksek olan ergenlerde depresif bulguların oluşmayabileceği gösterilmiştir. Özellikle de takım sporlarına katılmanın neden olduğu sosyal etkileşim egzersizin oluşturduğu ruh sağlığı faydalarından kısmen sorumlu olabilmektedir. Sosyal etkileşimin ve diğer sporcular ile iletişimin artması sporcuların kabullenme hissini artırabilir ve stresli yaşam olaylarının etkilerinin ve depresif bulguların azaltılmasında önemli bir rol oynar. Takım sporlarına katılım böylece ilerleyen yıllarda depresyon ve kaygı gibi ruhsal sağlık problemlerinin riskini azaltmaya yardımcı olabilir $(50,51)$. Bu çalışmadaki katılımcılar takım sporu yapan kızlardı. Bu sporcularda depresyon ve kaygı düzeylerinin spor yapmayanlara göre daha düşük düzeyde olması takım sporlarına katılmaya bağlı olarak oluşan sosyal etkileşimdeki artışın bir sonucu olarak meydana gelmiş olabilir.
$\mathrm{Bu}$ çalışmanın sınırlayıcı yanı az katıımcı ile yapılan kesitsel bir çalışma olması ve tüm verilerin katılımcıların kendi doldurdukları sübjektif anketlere dayanmasıdır. $\mathrm{Bu}$ tarz çalışmalara aynı zamanda bireysel spor yapan katılımcıları da dahil etmek, sporun etkilerinin yanı sıra takım sporunun da etkisini değerlendirmek açısından faydalı olacaktır. Çalışmanın güçlü yanı ise amaçlandığı gibi en az 5 yıl süre ile haftada en az 4 gün düzenli spor yapan kızların çalışmaya alınmış olmasıdır.

\section{SONUÇ}

$\mathrm{Bu}$ çalışmada egzersiz düzeyi yüksek olan ergenlerde depresyon ve kaygı bozukluklarının daha az görüldüğü gözlemlenmiştir. Bu bulgular daha az aktif olan ergenlerde aktivite seviyelerini artırmanın önemini göstermektedir. Çocuk ve ergenleri harekete teşvik etmenin ve egzersiz düzeylerini artırmanın ruh sağlıkları üzerine olumlu etkileri olacaktır. Aktivite seviyelerini ve spora katılımı artırmak bu bireyler arasında toplum hedefi olmalıdır. Egzersizin depresyon ve kaygı bozukluğu başta olmak üzere ruh sağlığı üzerindeki etkilerini ve bu etkileri hangi mekanizmalar ile oluşturduğunu daha net söyleyebilmek amacı ile daha çok katılımcının yer aldığı, iyi kurgulanmış prospektif çalışmaların yapılmasına intiyaç vardır.

Çıkar çatışması: Çalışmada herhangi bir kurum ve kişi ile çıkar çatışması bulunmamaktadır.

\section{Teşekkür}

$\mathrm{Bu}$ çalışmanın etik kurul formunun hazırlanmasında yardımcı olan Dr. Mehmet Açık'a ve ölçeklerin puanlamasının yapılmasında yol gösteren ve yardımcı olan Çocuk ve Ergen ruh Sağlığı ve Hastalıkları uzmanı Dr. Mehmet Oytun Hastürk'e teşekkürlerimi sunarım.

\section{Kaynaklar}

1. World Health Organization. Health for the world's adolescents: A second chance in the second decade (Accessed November 16, 2015). Available at: http://apps.who.int/adolescent/second-decade/

2. Kessler RC, Amminger GP, Aguilar- Gaxiolac S, Alonso J, Lee S, Ustün TB. Age of onset of mental disorders: a review of recent literature. Curr Opin Psychiatry 2007; 20: 359-64.

3. Balazs J, Miklósi M, Keresztény A, et al. Adolescent subthreshold-depression and anxiety: psychopathology, functional impairment and increased suicide risk. J Child Psychol Psychiatry 2013; 54 (6): 670-7.

4. Carli V, Hoven CW, Wasserman C, et al. A newly identified group of adolescents at "invisible" risk for psychopathology and suicidal behavior: findings from the SEYLE study. World Psychiatry 2014; 13(1):78-86.

5. Thapar A, Collishaw S, Pine DS, Thapar AK. Depression in adolescence. Lancet 2012; 379:1056-67. 
6. World Health Organization. Depression (2015). Available at: https://www.who.int/health-topics/depression

7. GBD 2017 Disease and Injury Incidence and Prevalence Collaborators. Global, regional, and national incidence, prevalence, and years lived with disability for 354 diseases and injuries for 195 countries and territories, 1990-2017: a systematic analysis for the Global Burden of Disease Study 2017. Lancet 2018; 10; 392 (10159): 1789-858.

8. Wilson S, Hicks B, Foster K, McGue M and lacono W. Age of onset and course of majör depressive disorder: associations with psychosocial functioning outcomes in adulthood. Psychol Med 2015; 45 (3): 505-14.

9. duRoscoät E, Legleye S, Guignard R, Husky M, Beck F. Risk factors for suicide attempts and hospitalizations in a sample of 39,542 French adolescents. J Affect Disord 2016; 15; 190:517-21.

10. Naicker K, Galambos NL, Zeng Y, Senthilselvan A, Colman I. Social, demographic, and health outcomes in the 10 years following adolescent depression. J Adolesc Health 2013; 52 (5): 533-8.

11. Glover J, Fritsch SL. Kids anxiety and social media: a review. Child Adolesc Psychiatr Clin N Am 2018; 27 (2): 171-82.

12. Meier SM, Mattheisen M, Mors O, Mortensen PB, Laursen TM, Penninx BW. Increased mortality among people with anxiety disorders: Total population study. Br J Psychiatry 2016; 209 (3): 216-21.

13. Calzo JP, Sonneville KR, Haines J, Blood EA, Field AE, Austin SB. The development of associations among body mass index, body dissatisfaction, and weight and shape concern in adolescent boys and girls. $J$ Adolesc Health 2012; 51 (5): 517-23.

14. Paxton SJ, Neumark-Sztainer D, Hannan PJ, Eisenberg ME. Body dissatisfaction prospectively predicts depressive mood and low self-esteem in adolescent girls and boys. J Clin Child Adolesc Psychol 2006; 35 (4): 539-49.

15. Lewinsohn PM, Striegel-Moore RH, Seeley JR. Epidemiology and natural course of eating disorders in young women from adolescence to young adulthood. J Am Acad Child Adolesc Psychiatr 2000; 39: 1284-92.

16. McGorry PD, Hickie IB, Yung AR, Pantelis C, Jackson HJ. Clinical staging of psychiatric disorders: a heuristic frame work for choosing earlier, safer and more effective interventions. Aust N Z J Psychiatry 2006; 40: 616-22.

17. Trainor S, Delfabbro P, Anderson S, Winefield A. Leisure activities and adolescent psychological well-being. J Adolesc 2010; 33 (1):173-86.

18. Rodriguez-Ayllon M, Cadenas-Sánchez C, Estévez-López F, et al. Role of Physical activity and sedentary behavior in the mental health of preschoolers, children and adolescents: A systematic review and metaanalysis. Sports Med. 2019; 49 (9): 1383-410.

19. Jorm AF, Wright A. Beliefs of young people and their parents about the effectiveness of interventions for mental disorders. Aust N Z J Psychiatry 2007; 41: 656-66.

20. Hallal PC, Andersen LB, Bull FC, Guthold R, Haskell W, Ekelund U. Global physical activity levels: Surveillance progress, pitfalls, and prospects. Lancet 2012; 380 (9838): 247-57.

21. World Health Organisation, Global Recommendations on Physical Activity for Health (2010). Available from: https://www.who.int/dietphysicalactivity/global-PA-recs-2010

22. Kaufman J, Birmaher B, Brent D, Rao U, Flynn C, Moreci P, et al. Schedule for affective disorders and schizophrenia for school-age children present and lifetime version (K-SADS-PL): initial reliability and validity data. J Am Acad Child Adolesc Psychiatry 1997; 36 (7): 980-8.

23. Saka MC, Uluşahin $A$, Batur $S$, Sütçü $A$ ve Kara $S$. Duygulanım bozuklukları ve şizofreni görüşme çizelgesiTürkçe formu güvenirlik çalışması. Türk Psikiyatri Dergisi 1998; 9 (4): 265-8.

24. Beck AT, Ward CH, Mendelson M, Mock J, Erbaugh J. An inventory for measuring depression. Arch Gen Psychiatry 1961; 4: 561-71.

25. Hisli N. Beck Depresyon Envanterinin üniversite öğrencileri için geçerliği, güvenirliği. Psikoloji dergisi 1989; 7 : 3-13.

26. Beck AT, Epstein N, Brown G, Steer RA. An inventory for measuring clinical anxiety: psychometric properties. J Consult Clin Psychol 1988; 56 (6): 893-7.

27. Ulusoy M, Şahin N, Erkmen H. Turkish version of the Beck Anxiety Inventory: Psychometric properties. J Cogn Psychother 1998; 12: 163-72.

28. Garner DM, Garfinkel PE. The Eating Attitudes Test: An index of the symptoms of anorexia nervosa. Psychol Med 1979; 9: 273-9. 
29. Savaşır I, Erol N. Yeme Tutum Testi: Anoreksi Nervoza belirtileri indeksi. Psikoloji Dergisi 1989; 7: 19-25.

30. Secord PF, Jourard SM. The appraisal of body-cathexis: body-cathexis and the self. J Consult Psychol 1953; 17 (5):343-7.

31. Hovardaoğlu S. Vücut algısı ölçeği. Psikiyatri, Psikoloji, Psikofarmakoloji Dergisi, Testler Özel Eki 1993; 1 (1): 26-7.

32. Teychenne M, Costigan SA, Parker K. The association between sedentary behaviour and risk of anxiety: a systematic review. BMC Public Health 2015; 15: 513.

33. Hoare E, Milton K, Foster C, Allender S. The associations between sedentary behaviour and mental health among adolescents: a systematic review. Int J Behav Nutr Phys Act 2016; 13: 108.

34. Bélair MA, Kohen DE, Kingsbury M, Colman I. Relationship between leisure time physical activity, sedentary behaviour and symptoms of depression and anxiety: evidence from a population-based sample of Canadian adolescents. BMJ Open. 2018; 17; 8 (10): e021119.

35. Biddle SJH, Ciaccioni S, Thomas G, Vergeer I. Physical activity and mental health in children and adolescents: an updated review of reviews and an analysis of causality. Psychol Sport Exerc 2019; 42: 146-55.

36. Mammen G, Faulkner G. Physical activity and the prevention of depression: A systematic review of prospective studies. Am J Prev Med 2013; 45 (5): 649-57.

37. Brown HE, Pearson N, Braithwaite RE, Brown WJ, Biddle SJ. Physical activity interventions and depression in children and adolescents: A systematic review and meta-analysis. Sports Med 2013; 43 (3): 195-206.

38. Larun L, Nordheim LV, Ekeland E, Hagen KB, Heian F. Exercise in prevention and treatment of anxiety and depression among children and young people. Cochrane Database Syst Rev 2006; 19 (3):CD004691.

39. Pascoe M, Bailey AP, Craike M, et al. Physical activity and exercise in youth mental health promotion: a scoping review. BMJ Open Sport Exerc Med 2020; $23 ; 6$ (1): e000677.

40. Bassett-Gunter R, McEwan D, Kamarhie A. Physical activity and body image among men and boys: A metaanalysis. Body Image 2017; 22: 114-28.

41. Babiss LA, Gangwisch JE. Sports participation as a protective factor against depression and suicidal ideation in adolescents as mediatedby self-esteem and social support. J Dev Behav Pediatr 2009; 30 (5): 376-84.

42. Strohle A, Graetz B, Scheel M, et al. The acute antipanic and anxiolytic activity of aerobic exercise in patients with panic disorder and healthy control subjects. J Psychiatr Res 2009; 43 (12): 1013-7.

43. Schuch FB, Stubbs B, Meyer J, et al. Physical activity protects from incident anxiety: A meta-analysis of prospective cohort studies. Depress Anxiety 2019; 36 (9): 846-58.

44. Paxton SJ, Neumark-Sztainer D, Hannan PJ, Eisenberg ME. Body dissatisfaction prospectively predicts depressive mood and low self-esteem in adolescent girls and boys. J Clin Child Adolesc Psychol 2006; 35 (4): 539-49.

45. Manaf NA, Saravanan C, Zuhrah B. The Prevalence and Inter-Relationship of Negative Body Image Perception, Depression and Susceptibility to Eating Disorders among Female Medical Undergraduate Students. J Clin Diagn Res 2016; 10 (3): VC01-VC04.

46. El Ansari W, Stock C, Phillips C, Mabhala A, Stoate M, Adetunji H. Does the association between depressive symptomatology and physical activity depend on body image perception? A survey of students from seven universities in the UK. Int J Environ Res Public Health 2011; 8 (2): 281-99.

47. Campbell A, Hausenblas HA. Effects of exercise interventions on body image: a meta-analysis. J Health Psychol 2009; 14 (6): 780-93.

48. Lubans D, Richards J, Hillman C, et al. Physical activity for cognitive and mental health in youth: a systematic review of mechanisms. Pediatrics 2016; 138 (3). pii: e20161642.

49. Mendonça G, Cheng L, Mélo E, Farias Júnior J. Physical activity and social support in adolescents: a systematic review. Heal Educ Res 2014; 29: 822-39.

50. Boone EM, Leadbeater BJ. Game on: diminishing risks for depressive symptoms in early adolescence through positive involvement in team sports. J Res Adolesc 2006; 16 (1): 79-90.

51. Sabiston CM, Jewett R, Ashdown-Franks G, Belanger M, BrunetJ, O'Loughlin E, et al. Number of years of team and individual sport participation during adolescence and depressive symptoms in early adulthood. $J$ Sport Exerc Psychol 2016; 38 (1):105-10. 